Terbit online pada laman : http://teknosi.fti.unand.ac.id/

\title{
Penerapan Prediksi Produksi Padi Menggunakan Artificial Neural Network Algoritma Backpropagation
}

\author{
Hasdi Putra ${ }^{a,}{ }^{*}$, Nabilah Ulfa Walmi ${ }^{b}$ \\ ${ }^{a, b}$ Program Studi Sistem Informasi Universitas Andalas, Kampus Unand Limau Manis, Padang 25163
}

\section{INFORMASI ARTIKEL}

Sejarah Artikel:

Diterima Redaksi: 15 Juli 2020

Revisi Akhir: 02 September 2020

Diterbitkan Online: 05 September 2020

\section{KATA KUNCI}

prediksi produksi padi

artificial neural network

backpropagation

hidden layer

akurasi

\section{KORESPONDENSI}

E-mail: hasdiputra@it.unand.ac.id *

\section{A B S T R A C T}

Prediksi produksi padi menjadi penting dilakukan untuk menunjang pembangunan nasional sektor pertanian pada suatu negara atau wilayah. Artificial Neural Network (ANN) termasuk metode yang terbaik dalam melakukan prediksi. Masalah utamanya adalah bagaimana menentukan jumlah neuron dan hidden layer yang optimal sehingga akurasi prediksinya tinggi. Artikel ini bertujuan untuk merancang arsitektu ANN unutk melakukan prediksi terhadap produksi padi menggunakan ANN dengan algortima backpropagation. Tahapan penelitian yang dilakukan adalah mengumpulkan data produksi padi, melakukan pre-processing data, memproses prediksi, dan pengujian akurasi dan error serta implementasi. Dalam memproses prediksi dilakukan sesuai dengan rancangan model prediksi, yaitu parameter epoch, momentum, learning rate, hidden layer untuk menghasilkan keakuratan yang tinggi. Temuan yang diperolah berupa rancangan optimal untuk melakukan prediksi yaitu dengan menggunakan multilayer. Hasil pengujian sistem prediksi produksi padi yang terdiri dari 75 kali pengujian pada di 19 daerah di Sumatera Barat, diperoleh tingkat akurasi mencapai $88,14 \%$ atau dengan tingkat error yang relatif rendah yaitu $11,86 \%$.

\section{PENDAHULUAN}

Prediksi produksi padi merupakan suatu yang vital bagi Indonesia khususnya di sektor pertanian [1]. Dengan jumlah penduduk yang mencapai 267 juta orang serta tingkat konsumsi beras mencapai $124,89 \mathrm{~kg} / \mathrm{kapita} / \mathrm{tahun}$, perencanaan pembangunan produksi padi menjadi semakin strategis [2]. Untuk efektifitas perencanaan pembangunan sektor pertanian, akurasi dari prediksi produksi padi menjadi semakin krusial [3]. Untuk memperoleh akurasi yang baik, beragam metode sudah dikembangkan. Metode dan teknik prediksi yang berkembang sudah direview pada penelitian sebelumnya [4], [5]. Support Vector Machines (SVM) memiliki kelebihan dalam menginterprestasi hasil, tingkat error yang rendah, dan juga dapat menghasilkan prediksi yang baik, tapi memiliki kelemahan pada saat training dengan kumpulan data besar sehingga training jadi lambat [6]. K-Nearest Neighbor (KNN) memiliki kelebihan efektif terhadap data yang berukuran besar, dan handal terhadap data yang memiliki banyak noise, namun juga memiliki kekurangan yaitu perlunya menghitung satu persatu data testing terhadap semua data training [7], dan sensitif terhadap data pre processing [8].

Artificial Neural Network (ANN) atau Jaringan Syaraf Tiruan (JST) merupakan suatu sistem pemrosesan informasi dengan suatu karakteristik menyerupai sistem saraf pada manusia yang dapat memecahkan masalah SVM dan KNN dengan melakukan training data yang besar dan ANN memiliki kemamuan untuk mentoleransi kesalahan sehingga dapat menghasilkan prediksi yang baik [6], [9], [10]. Selain itu metode ini juga dapat digunakan untuk memodelkan hubungan yang kompleks antara masukan (input) dan keluaran (output) dalam menemukan polapola pada data [11]. Namun masalahnya adalah ANN memiliki kelemahan yaitu sulit untuk mengetahui berapa banyak neuron dan lapisan yang diperlukan, dan mengalami perlambatan saat learning [12]. 
Dalam metode ANN, terdapat beberapa algoritma yang telah digunakan salah satunya adalah backpropagation [13]. Algoritma Backpropagation merupakan salah satu prosedur yang paling populer, efektif, dan mudah dipelajari pada jaringan multilayer yang kompleks untuk mengoptimalkan pelatihan jaringan saraf tiruan [14]. Backpropagation melakukan pembelajaran terbimbing (supervised learning) yang digunakan pada jaringan multi-layer yang terdiri dari beberapa hidden-layer yang bertujuan untuk meminimalkan error terhadap jaringan yang menghasilkan keluaran (output) [15]. Menggunakan fungsi pelatihan (training functions) variabel laju pemahaman (traingdx) untuk mempercepat pelatihan backpropagation, yang merupakan kombinasi dari parameter laju pemahaman (learning rate) dan momentum [16] sehingga mendapatkan hasil yang relatif lebih akurat [17]. Makalah ini membahas bagaimana menentukan banyak neuron dan jumlah layer yang diperlukan untuk prediksi hasil produksi padi.

\section{METODE}

Dalam pelaksanaan penelitian ini, ada beberapa tahapan yang dilaksanakan yaitu mengumpulkan data, melakukan pemrosesan awal, memprediksi produksi padi, melakukan pengujian akurasi dan implementasi seperti pada gambar 1 .

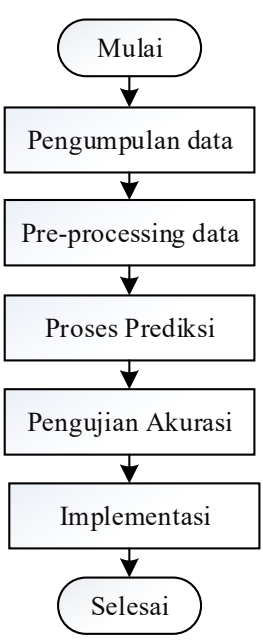

Gambar 1. Tahapan Penelitian

Data penelitian ini berasal dari Dinas Tanaman Pangan, Hortikultura, dan Perkebunan Provinsi Sumatera Barat sebagai institusi yang bertanggungjawab dalam mewujudkan kemandirian pangan dan meningkatkan kualitas hasil pertanian.

\subsection{Pengumpulan Data}

Data yang dikumpulkan merupakan data produksi padi selama 5 (lima) tahun, yang berasal dari dari 19 Kota/Kabupaten di Sumatera Barat. Data yang dikumpulkan untuk masing-masing kota/kabupaten adalah; (1) data target luas tanam padi (Ha), (2) data target luas panen padi (Ha), (3) data target produktifitas padi (ton/Ha), (4) data target produksi padi (ton).

\subsection{Pre-Processing Data}

Pada tahap ini, target luas tanam padi, target luas panen padi dan target produktifitas padi dari tahun 2013-2017 dan target produksi padi dari tahun 2013-2018 tersebut dikelompokkan menjadi 2 jenis data, yaitu data latih (training) dan data uji (testing) sebagai data input. Tahap ini bertujuan juga untuk mempersiapkan data agar dapat digunakan dalam prediksi. Selanjutnya melakukan normalisasi atau transformasi data, karena lapisan tersembunyi (hidden layer) menggunakan fungsi aktivasi sigmoid biner atau logsig untuk lapisan tersembunyi dan purelin untuk lapisan keluaran. Proses normalisasi atau transformasi memiliki tujuan untuk mempermudah perhitungan dan mendapatkan hasil prediksi yang lebih akurat.

\subsection{Proses Prediksi Produksi Padi}

Proses prediksi produksi padi menggunakan metode Artificial Neural Network (ANN) Backpropagation dapat ditunjukkan seperti pada gambar 2 berikut;

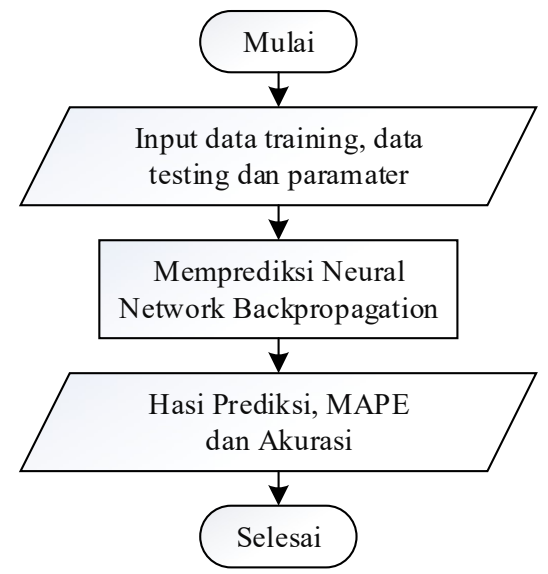

Gambar 2. Flowchart Prediksi Produksi Padi dengan Jaringan Saraf Tiruan Backpropagation

Pada rancangan prediksi produksi padi menggunakan ANN Backrpopagation ini, dimulai dengan melakukan penginputan data uji dan data latih. Data uji dan data latih dapat dikatakan sebagai variabel input dan data target. variabel input terdiri dari data target luas tanam padi, target luas panen padi dan target produktivitas padi tahun 2013-2017. Dan variabel target yaitu data target produksi padi tahun 2013-2017. Output merupakan hasil prediksi produksi padi tahun 2018.

Untuk merancang arsitektur metode ANN Backpropagation yang menghasilkan prediksi yang optimal, maka dilakukan penentuan atau penginputan jumlah nilai parameter-parameter yang digunakan, seperti jumlah hidden layer, laju pemahaman (learningrate), maksimum iterasi (epoch), dan momentum dengan menggunakan proses trial and error. Setelah menentukan jenis data dan parameter, prediksi dilakukan dengan metode ANN Backpropagation berdasarkan langkah-langkah arahan Laurene Fausett [18]. Selanjutnya, hasil prediksi yang diperoleh dievaluasi nilai errornya dengan menggunakan MAPE untuk memperoleh tingkat akurasi pada prediksi.

\subsection{Pengujian akurasi dan error}

Pada tahapan ini dilakukan pengujian hasil prediksi yang sudah diperoleh dengan cara melihat tingkat keakuratan dan error pada sistem. Pengujian dilakukan kepada masing-masing data training dan data testing. Pengujian bertujuan untuk mengetahui sistem kerja input, proses dan output apakah sesuai dengan tujuan yang diharapkan. Cara menghitung nilai error digunakan MAPE (Mean 
Average Precentage Error). Nilai MAPE menunjukkan seberapa banyak kesalahan dalam hasil prediksi dibandingkan dengan nilai aktual. Mean Absolute Percentage Error (MAPE) dihitung menggunakan kesalahan mutlak dalam setiap periode dibagi dengan nilai-nilai yang diamati yang jelas untuk periode tersebut. Semakin kecil nilai MAPE maka semakin baik kinerja prediksi [27]. Untuk menghitung akurasi terhadap prediksi yang dilakukan, maka sebuah akurasi $100 \%$ dikurangi dengan nilai MAPE [19].

$$
\begin{aligned}
& \text { MAPE }=\frac{\sum_{t=1}^{n} \frac{\left|x_{t}-y_{t}\right|}{x_{t}}}{n} \times 100 \% \\
& \text { Akurasi }=100 \%-\text { MAPE... }
\end{aligned}
$$

Dimana $x_{t}$ adalah nilai target data asli pada periode $t$, sedangkan $\mathrm{y}_{\mathrm{t}}$ merupakan nilai prediksi pada periode $\mathrm{t}$ dan $\mathrm{n}$ adalah banyaknya data prediksi pada periode t. MAPE digunakan dalam penelitian ini untuk mengevaluasi kinerja berbagai jenis model prediksi. Semakin kecil MAPE maka semakin baik model prediksinya [20] seperti pada tabel 1 .

Tabel 1. Kriteria Skal MAPE

\begin{tabular}{cc} 
Skala MAPE & Kriteria \\
\hline$<10 \%$ & Sangat Baik \\
\hline $10 \%-20 \%$ & Baik \\
\hline $20 \%-50 \%$ & Cukup \\
\hline$>50 \%$ & Buruk \\
\hline
\end{tabular}

\subsection{Implementasi}

Pada tahapan ini, hasil penelitian prediksi jaringan saraf tiruan backpropagation diterapkan pada GUI MATLAB agar mempermudah user dalam pengoperasian model yang telah dibangun.

\section{HASIL}

\subsection{Pengumpulan Data}

Hasil dari pengumpulan data adalah berupa data target luas tanam padi, target luas panen padi, dan target produktifitas padi dari tahun 2013-2017 serta target produksi padi dari tahun 2013-2018. Pada tabel 2 berikut ini akan menunjukkan data yang digunakan.

Tabel 2. Data Target Produksi Tahun 2013

\begin{tabular}{lrrrr}
\hline Kabupaten/Kota & X1 & X2 & X3 & Y \\
\hline A= Kota Padang & 13.511 & 13.323 & 5,64 & 75.168 \\
\hline $\mathrm{B}=$ Kota Bukittinggi & 836 & 808 & 5,84 & 4.715 \\
\hline $\mathrm{C}=$ Kota Payakumbuh & 7.315 & 7.258 & 5,55 & 40.282 \\
\hline $\mathrm{D}=$ Kota Padang Panjang & 1.675 & 1.782 & 5,18 & 9.231 \\
\hline $\mathrm{E}=$ Kota Solok & 2.296 & 2.196 & 5,90 & 12.956 \\
\hline $\mathrm{F}=$ Kota Sawahlunto & 2.841 & 2.785 & 5,01 & 13.953 \\
\hline $\mathrm{G}=$ Kota Pariaman & 6.063 & 6.179 & 5,10 & 31.513 \\
\hline $\mathrm{H}=$ Kabupaten Pasaman & 50.887 & 46.218 & 5,11 & 236.266 \\
\hline $\mathrm{I}=$ Kabupaten Pasaman Barat & 26.631 & 27.126 & 4,67 & 126.678 \\
\hline $\mathrm{J}=$ Kabupaten Lima Puluh Kota & 47.123 & 47.530 & 4,85 & 230.521 \\
\hline $\mathrm{K}=$ Kabupaten Agam & 55.553 & 55.287 & 5,44 & 300.706 \\
\hline $\mathrm{L}=$ Kabupaten Tanah Datar & 43.525 & 43.742 & 5,75 & 251.517 \\
\hline $\mathrm{M}$. Kab. Padang Pariaman & 50.806 & 52.045 & 5,08 & 264.389 \\
\hline $\mathrm{N}=$ Kabupaten Solok & 61.360 & 60.655 & 5,56 & 337.242 \\
\hline $\mathrm{O}=$ Kabupaten Solok Selatan & 29.521 & 26.788 & 5,00 & 133.941 \\
\hline $\mathrm{P}=$ Kabupaten Sijunjung & 18.339 & 18.689 & 4,52 & 84.530 \\
\hline $\mathrm{Q}=$ Kabupaten Dharmasraya & 15.670 & 15.230 & 4,60 & 70.058 \\
\hline & & & &
\end{tabular}

102 Hasdi Putra

\begin{tabular}{lrrrr}
\hline $\mathrm{R}=$ Kabupaten Pesisir Selatan & 57.483 & 57.494 & 5,00 & 287.470 \\
\hline $\mathrm{S}=$ Kabupaten Mentawai & 119 & 296 & 3,50 & 1.036 \\
\hline $\mathrm{X} 1=$ target luas tanam padi $(\mathrm{Ha}) ; \mathrm{X} 2=$ target luas panen padi $(\mathrm{Ha}) ; \mathrm{X} 3=$ \\
target produktivitas padi (Ton/Ha); $\mathrm{Y}=$ target produksi padi (Ton).
\end{tabular}

\subsection{Pre-Processing}

Data produksi padi dan variabel lainnya dibagi atas dua kelompok yaitu sebagai data latih (training) dan data uji (testing). Maka proporsi pembagian data training dan data testing yang digunakan dalam penelitian ini yaitu $70 \%$ data training berjumlah 66 data setiap variabel dan $30 \%$ data testing berjumlah 29 data setiap variabel. Setelah data terbagi menjadi dua bagian, selanjutnya dilakukan pemeriksaan agar data tersebut valid dan siap digunakan untuk melakukan prediksi produksi padi. Setiap data input dilakukan normalisasi. Setelah data terbagi menjadi dua bagian, selanjutnya akan dilakukan pemeriksaan agar tidak ada yang missing hingga data tersebut valid dan dapat digunakan dalam melakukan prediksi produksi padi. Karena pada penelitian ini menggunakan fungsi aktivasi sigmoid biner yang mempunyai rentang nilai 0 hingga 1 , maka setiap data input melakukan normalisasi atau transformasi. Normalisasi data dilakukan dengan menggunakan persamaan (3) berikut :

$$
X^{\prime}=\frac{0,8\left(X-X_{\min }\right)}{X_{\max }-X_{\min }}+0,1
$$

Data primer yang digunakan merupakan data dari Dinas Tanaman Pangan, Hortikultura, dan Perkebunan Provinsi Sumatera Barat diproses terlebih dahulu sebelum diolah pada MATLAB. Data tersebut dimasukkan ke dalam Microsoft Excel, data di kelompokkan berdasarkan data input dan data target. Lalu dilakukan proses normalisasi. Setelah itu data siap untuk di input pada MATLAB. Pada tabel 3 berikut ini akan menunjukkan hasil data setelah melakukan proses normalisasi pada data tahun 2013.

Tabel 3. Data Normalisasi

\begin{tabular}{ccccc}
\hline $\begin{array}{l}\text { Kabupaten/ } \\
\text { Kota }\end{array}$ & $\mathbf{X 1}$ & $\mathbf{X 2}$ & $\mathbf{X 3}$ & $\mathbf{Y}$ \\
\hline $\mathrm{A}$ & 0.2325 & 0.2306 & 0.1003 & 0.2446 \\
\hline $\mathrm{B}$ & 0.1079 & 0.1077 & 0.1003 & 0.1072 \\
\hline $\mathrm{C}$ & 0.1716 & 0.1710 & 0.1003 & 0.1765 \\
\hline $\mathrm{D}$ & 0.1162 & 0.1172 & 0.1002 & 0.1160 \\
\hline $\mathrm{E}$ & 0.1223 & 0.1213 & 0.1003 & 0.1232 \\
\hline $\mathrm{F}$ & 0.1276 & 0.1271 & 0.1002 & 0.1252 \\
\hline $\mathrm{G}$ & 0.1593 & 0.1604 & 0.1002 & 0.1594 \\
\hline $\mathrm{H}$ & 0.5998 & 0.5539 & 0.1002 & 0.5587 \\
\hline $\mathrm{I}$ & 0.3614 & 0.3663 & 0.1002 & 0.3450 \\
\hline $\mathrm{J}$ & 0.5628 & 0.5668 & 0.1002 & 0.5475 \\
\hline $\mathrm{K}$ & 0.6456 & 0.6430 & 0.1003 & 0.6844 \\
\hline $\mathrm{L}$ & 0.5274 & 0.5296 & 0.1003 & 0.5885 \\
\hline $\mathrm{M}$ & 0.5990 & 0.6112 & 0.1002 & 0.6136 \\
\hline $\mathrm{N}$ & 0.7027 & 0.6958 & 0.1003 & 0.7556 \\
\hline $\mathrm{O}$ & 0.3898 & 0.3630 & 0.1002 & 0.3592 \\
\hline $\mathrm{P}$ & 0.2799 & 0.2834 & 0.1002 & 0.2628 \\
\hline $\mathrm{Q}$ & 0.2537 & 0.2494 & 0.1002 & 0.2346 \\
\hline $\mathrm{R}$ & 0.6646 & 0.6647 & 0.1002 & 0.6586 \\
\hline $\mathrm{S}$ & 0.1009 & 0.1026 & 0.1001 & 0.1000
\end{tabular}

X1: target luas tanam padi yang telah dinormalisasi, X2: target luas panen padi yang telah dinormalisasi. X3: target produktivitas padi yang telah dinormalisasi dan $\mathrm{Y}$ : target produksi padi yang telah dinormalisasi 


\subsection{Proses Prediksi}

\subsubsection{Perancangan Arsitektur Model ANN}

Rincian rancangan model prediksi produksi padi seperti yang ditunjukkan pada Tabel 4

Tabel 4. Rancangan Model ANN Multilayer Prediksi

\begin{tabular}{lll} 
Parameter & Jumlah & Keterangan \\
\hline Input Layer & 3 neuron & $\begin{array}{l}\text { Target Luas Tanam Padi; } \\
\text { Target Luas Panen Padi; } \\
\text { Target Produktifitas Padi }\end{array}$ \\
\hline Hidden Layer & trial and error & 3 neuron \\
\hline Output Layer & 1 neuron & Produksi padi \\
\hline Bobot Awal & trial and error & BB : 0.05 BA : 0.08 \\
& & Bilangan acak antara 0.05- \\
& & 0.08 \\
\hline Learning Rate & Trial and error & $0.1-0.5$ \\
\hline Momentum & Trial and error & $0.5-0.9$ \\
\hline Epoch & Trial and error & $100-200$ (dengan \\
& & interval 50) \\
\hline Fungsi Aktivasi & 2 & Logsig dan Purelin \\
\hline
\end{tabular}

Dari tabel 4 dapat digambarkan arsitekturnya seperti gambar 3 berikut;

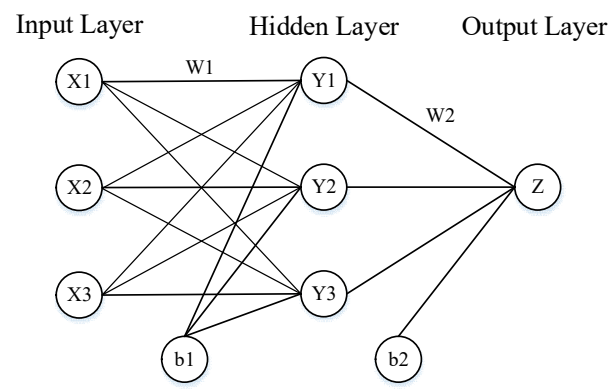

Gambar 3. Arsitektur ANN Prediksi Produksi Padi

Arsitektur ANN yang dirancangan menggunakan tiga neuron pada input layer yaitu target luas tanam padi, target luas panen padi dan target produktifitas padi. Hidden layer terdiri dari tiga (3) neuron diperoleh dari proses trial dan error. Bobot yang digunakan adalah rentang 0.05 sampai dengan 0.08 . Output layer berupa prediksi produksi padi dengan 1 neuron.

\subsubsection{Aplikasi Pengujian Prediksi}

Pada halaman prediksi terdapat pop up menu untuk memilih untuk memprediksi data latih atau data uji yang telah di input-kan sebelumnya pada Microsoft Excel. Setelah data uji atau data input dipilih, lalu input nilai-nilai pada setiap parameter yaitu, Epoch, Learning Rate, Momentum, dan Hidden Layer. Saat semua nilai telah terisi, maka pengguna menekan button prediksi untuk melakukan proses prediksi dengan metode ANN Backpropagation. Lalu sistem akan menampilkan hasil prediksi pada tabel hasil prediksi padi, yang dibedakan atas dua kolom, yaitu kolom aktual (target produksi) yang berasal dari variabel (data) target produksi padi, dan kolom prediksi padi yang merupakan hasil prediksi sistem. Setelah hasil prediksi ditampilkan, maka dilakukan perhitungan error dan akurasi. Perhitungan error dilakukan dengaan rumus MAPE. Sistem akan menghasilkan akurasi $100 \%$ jika nilai error bernilai 0, atau dapat dikatakan hasil prediksi sistem mirip atau sama dengan nilai aktual. Antaramuka aplikasi pengujian prediksi produksi padi seperti ditunjukkan pada gambar 4.

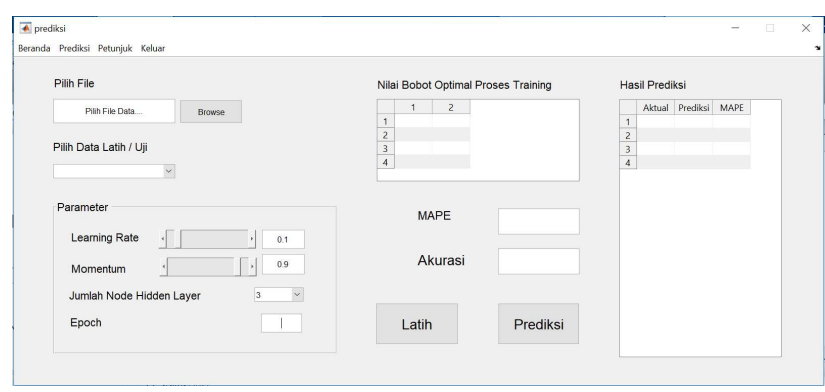

Gambar 4. Antarmuka Halaman Prediksi

\subsubsection{Pengujian Aplikasi}

Setelah sistem selesai dibangun, maka dilakukan pengujian untuk menghitung akurasi dan nilai error pada prediksi produksi padi menggunakan jaringan saraf tiruan backpropagation. Ada dua jenis pengujian, yaitu pengujian fungsionalitas sistem dan pengujian aplikasi. Pengujian sistem ini dilakukan dengan fungsionalitas dari sudut pandang user (pengguna). Format dan pengujian yang dilakukan terhadap sistem ditunjukkan pada tabel 5 berikut ini.

Tabel 5. Pengujian Fungsionalis Sistem

\begin{tabular}{lllll}
\hline No. & $\begin{array}{l}\text { Komponen } \\
\text { Pengujian }\end{array}$ & Input & Output & Status \\
\hline 1. & $\begin{array}{l}\text { Halaman } \\
\text { Beranda }\end{array}$ & $\begin{array}{l}\text { User memilih } \\
\text { menu beranda }\end{array}$ & $\begin{array}{l}\text { Menampilkan } \\
\text { halaman } \\
\text { beranda }\end{array}$ & OK \\
\hline 2. & $\begin{array}{l}\text { Halaman } \\
\text { Prediksi }\end{array}$ & $\begin{array}{l}\text { User memilih } \\
\text { menu prediksi }\end{array}$ & $\begin{array}{l}\text { Menampilkan } \\
\text { halaman } \\
\text { prediksi }\end{array}$ & OK \\
\hline 3. & $\begin{array}{l}\text { Halaman } \\
\text { Petunjuk }\end{array}$ & $\begin{array}{l}\text { User memilih } \\
\text { menu petunjuk }\end{array}$ & $\begin{array}{l}\text { Menampilkan } \\
\text { halaman } \\
\text { petunjuk }\end{array}$ & OK \\
\hline
\end{tabular}

Dari tabel 5 berdasarkan pengujian input dan output pada setiap komponen pengujian yaitu halaman beranda, halaman prediksi, dan halaman petunjuk dapat dikatakan bahwa fungsionalitas sistem berhasil. Hasil pengujian parameter prediksi produksi padi menggunakan jaringan saraf tiruan backpropagation seperti yang ditunjukkan pada tabel 6 .

Tabel 6. Hasil Prediksi dengan Pengujian Parameter

\begin{tabular}{|c|c|c|c|c|}
\hline Epoch & $\begin{array}{l}\text { Momen } \\
\text { tum }\end{array}$ & $\begin{array}{c}\text { Learning } \\
\text { Rate }\end{array}$ & MAPE (\%) & Akurasi (\%) \\
\hline \multirow[t]{21}{*}{200} & \multirow[t]{5}{*}{0,5} & 0,1 & 13,271129 & 86,728871 \\
\hline & & 0,2 & 12,005893 & 87,994107 \\
\hline & & 0,3 & 11,886828 & 88,113172 \\
\hline & & 0,4 & 11,865150 & 88,134850 \\
\hline & & 0,5 & 11,861308 & 88,138692 \\
\hline & \multirow[t]{5}{*}{0,6} & 0,1 & 13,274849 & 86,725151 \\
\hline & & 0,2 & 12,006093 & 87,993907 \\
\hline & & 0,3 & 11,886851 & 88,113149 \\
\hline & & 0,4 & 11,865101 & 88,134899 \\
\hline & & 0,5 & 11,861311 & 88,138689 \\
\hline & \multirow[t]{5}{*}{0,7} & 0,1 & 13,273208 & 86,726792 \\
\hline & & 0,2 & 12,005597 & 87,994403 \\
\hline & & 0,3 & 11,886781 & 88,113219 \\
\hline & & 0,4 & 11,902695 & 88,097305 \\
\hline & & 0,5 & 11,861312 & 88,138688 \\
\hline & \multirow[t]{5}{*}{0,8} & 0,1 & 13,275736 & 86,724264 \\
\hline & & 0,2 & 12,006159 & 87,993841 \\
\hline & & 0,3 & 11,886636 & 88,113364 \\
\hline & & 0,4 & 11,865135 & 88,134865 \\
\hline & & 0,5 & 11,861316 & 88,138684 \\
\hline & 0,9 & 0,1 & 13,276099 & 86,723901 \\
\hline
\end{tabular}

Hasdi Putra 


\begin{tabular}{lll}
0,2 & 12,005949 & 87,994051 \\
\hline 0,3 & 11,886803 & 88,113197 \\
\hline 0,4 & 11,865106 & 88,134894 \\
\hline 0,5 & 11,861320 & 88,138680
\end{tabular}

Berdasarkan hasil pengujian sistem terhadap rancangan model parameter-parameter yang telah ditentukan, maka diperoleh parameter yang menghasilkan nilai MAPE terkecil dan akurasi terbesar, yaitu dengan epoch sebesar 200, momentum sebesar 0,5, dan learning rate sebesar 0,5 . Nilai MAPE yang didapatkan yaitu $11,86 \%$ dan nilai akurasi atau keakuratan prediksi sebesar $88,14 \%$.

\subsubsection{Post-Processing Data}

Setelah proses prediksi, maka akan didapatkan nilai output atau hasil prediksi, dimana data awal sebagai data input telah dilakukan proses normalisasi atau transformasi. Jadi untuk data prediksi yang baru dihasilkan perlu dilakukan proses denormalisasi. Proses ini disebut dengan post-processing, yaitu proses dimana nilai output yang menghasilkan nilai dengan rata rata sama dengan nol, maka dalam proses ini akan mengembalikan nilai tersebut sesuai dengan data awal atau data yang asli. Nilai output yang dihasilkan pada proses simulasi adalah nilai dari data yang telah dinormalisasi pada langkah awal. Denormalisasi data dilakukan dengan menggunakan persamaan (4) berikut:

$$
X=\frac{\left(X^{\prime}-0,1\right) \times X_{\max }-X_{\min }}{0,8}+X_{\min }
$$

Setelah seluruh proses prediksi dilakukan pada MATLAB, data hasil prediksi disalin, dipindahkan, dan diolah pada Microsoft Excel untuk melakukan proses denormalisasi. Prediksi produksi padi yang dilakukan dengan menggunakan metode jaringan saraf tiruan backpropagation sehingga diperoleh model yang menghasilkan akurasi dan tingkat kesalahan (error) yang optimal. Hasil denormalisasi sekaligus hasil prediksi produksi padi pada kabupaten/kota di provinsi Sumatera Barat untuk tahun 2018 ditunjukkan pada tabel 7 berikut.

Tabel 7. Hasil Denormalisasi Prediksi Produksi

\begin{tabular}{ccc} 
Kabupaten/Kota & $\begin{array}{c}\text { Sebelum } \\
\text { Denormalisasi }\end{array}$ & $\begin{array}{c}\text { Setelah } \\
\text { Denormalisasi }\end{array}$ \\
\hline $\mathrm{A}$ & 0,288718 & 97.808 \\
\hline $\mathrm{B}$ & 0,110297 & 6.316 \\
\hline $\mathrm{C}$ & 0,182405 & 43.292 \\
\hline $\mathrm{D}$ & 0,119414 & 10.991 \\
\hline $\mathrm{E}$ & 0,126920 & 14.84 \\
\hline $\mathrm{F}$ & 0,139737 & 21.413 \\
\hline $\mathrm{G}$ & 0,170091 & 36.977 \\
\hline $\mathrm{H}$ & 0,670671 & 293.667 \\
\hline $\mathrm{I}$ & 0,443951 & 177.408 \\
\hline $\mathrm{J}$ & 0,728241 & 323.188 \\
\hline $\mathrm{K}$ & 0,900000 & 411.263 \\
\hline $\mathrm{L}$ & 0,679379 & 298.132 \\
\hline $\mathrm{M}$ & 0,754264 & 336.532 \\
\hline $\mathrm{N}$ & 0,872649 & 397.238 \\
\hline $\mathrm{O}$ & 0,408359 & 159.157 \\
\hline $\mathrm{P}$ & 0,328559 & 118.237 \\
\hline $\mathrm{Q}$ & 0,301161 & 104.188 \\
\hline
\end{tabular}

104 Hasdi Putra

\begin{tabular}{ccc}
\hline $\mathrm{R}$ & 0,799787 & 359.876 \\
\hline $\mathrm{S}$ & 0,121186 & 11.9 \\
\hline
\end{tabular}

Untuk memprediksi target produksi padi pada tahun tertentu, sudah berhasil di rancang suatu aplikasi menggunakan metode Artificial Neural Network algoritma Backpropagation. Aplikasi tersebut sudah dilakukan pengujian untuk memprediksi target produksi tahun berikutnya. Dari pengolahan data, diperoleh grafik perbadingan jumlah produksi padi aktual yang dicapai pada tahun 2018 dengan prediksi target produksi padi pada Kota/Kabupaten di Sumatera Barat, Indonesia seperti yang ditunjukkan oleh gambar 5 .

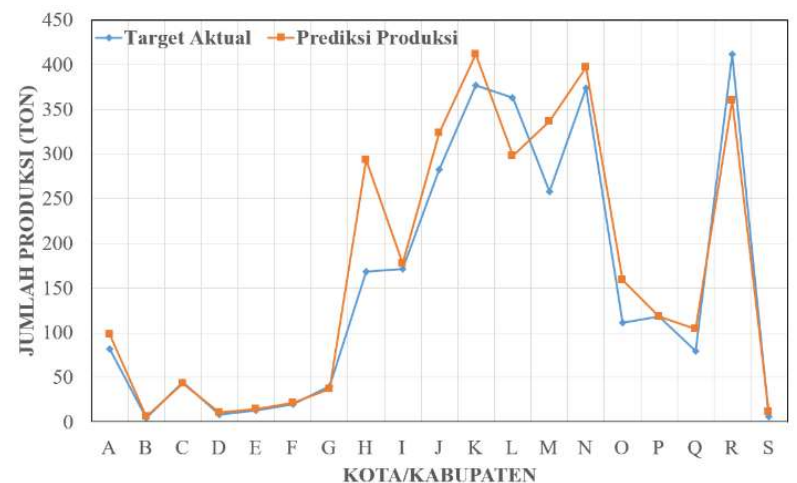

Gambar 5. Perbandingan Aktual Produksi dengan Prediksi

Dari perbandingan target aktual produksi dengan prediksi target produksi, diperoleh tingkat akurasi hasil prediksi tersebut. Persentase keakuratan prediksi target produksi padi yang dihasilkan aplikasi dengan produksi padi aktual dapat ditunjukkan pada Tabel 8.

Tabel 8. Persentase Akurasi Prediksi Produksi Padi

\begin{tabular}{crrr}
$\begin{array}{c}\text { Kota/ } \\
\text { Kabupaten }\end{array}$ & $\begin{array}{r}\text { Produksi } \\
\text { Aktual } \\
\text { (Ton) }\end{array}$ & $\begin{array}{r}\text { Prediksi } \\
\text { Produksi } \\
\text { (Ton) }\end{array}$ & $\begin{array}{r}\text { Akurasi } \\
\text { Prediksi } \\
(\%)\end{array}$ \\
\hline A & 168.712 & 293.667 & 42,931 \\
\hline B & 171.438 & 177.408 & 97,307 \\
\hline C & 282.574 & 323.188 & 87,797 \\
\hline D & 376.965 & 411.263 & 91,971 \\
\hline E & 362.553 & 298.132 & 84,394 \\
\hline F & 257.734 & 336.532 & 74,414 \\
\hline G & 374.063 & 397.238 & 94,538 \\
\hline H & 111.424 & 159.157 & 70,475 \\
\hline I & 118.473 & 118.237 & 99,860 \\
\hline J & 79.690 & 104.188 & 81,146 \\
\hline K & 411.263 & 359.876 & 88,865 \\
\hline L & 45.081 & 43.292 & 98,123 \\
\hline M & 4.520 & 6.316 & 96,720 \\
\hline N & 8.765 & 10.991 & 96,227 \\
\hline O & 82.054 & 97.808 & 88,092 \\
\hline P & 12.883 & 14.840 & 96,900 \\
\hline Q & 19.987 & 21.413 & 97,971 \\
\hline R & 6.505 & 11.900 & 90,493 \\
\hline S & 40.224 & 36.977 & 96,411 \\
\hline & & &
\end{tabular}




\section{PEMBAHASAN}

\subsection{Perancangan Arsitektur ANN}

Teknik perancangan arsitektur sudah banyak dibahas [21], [22], [23]. Rancangan menggunakan multilayer maka layer terbagi atas 3 layer yaitu [24]; (1) lapisan masukan (input layer) yang jumlahnya dapat disesuaikan dengan variabel input. (2) Lapisan tersembunyi (hidden layer) yang jumlahnya didapatkan dengan proses trial and error yaitu berjumlah 3 disesuaikan dengan jumlah variabel input. Pada lapisan ini digunakan fungsi aktivasi sigmoid biner logsig yang berguna dalam mengirimkan suatu informasi dari input layer melalui bobot ke neuron pada hidden layer. (3) Lapisan keluaran (output layer) yang jumlahnya disesuaikan dengan variabel output. Pada lapisan ini digunakan fungsi aktivasi purelin yang berguna untuk menghasilkan output yang memiliki range yang sama dengan input. Desain yang diusulkan adalah multilayer dengan input 3 neuron, hiden layer trail and error dan output 1 neuron. Desain multilayer cenderung mempunyai akurasi yang baik [25]. Hal yang sama juga dilakukan dan lebih efektif [26].

Variabel penelitian dibagi menjadi 2 yaitu data input dan data target. Untuk variabel input data yang digunakan adalah target luas tanam padi, target luas panen padi, dan target produktivitas padi dari tahun 2013-2017. Variabel target adalah target produksi padi pada setiap kabupaten/kota di Sumatera Barat dari tahun 2013-2018. Karena menggunakan proses trial and error, jadi diperlukan penentuan terhadap parameter-parameter yang digunakan. Arsitektur layer yang digunakan yaitu multilayer yang terdiri dari lapisan input, hidden, dan output, pada input layer telah ditentukan atas 3 variabel yaitu produksi, luas panen, dan produktivitas padi, pada hidden layer jumlah neuron tersembunyi harus kurang dari dua kali ukuran input layer [27], karena jumlah neuron yang optimal ditentukan dengan proses trial and error sehingga jumlah hidden layer berjumlah kurang dari 6 neuron yaitu 3 hidden layer yang juga disamakan dengan jumlah variabel input.

Selanjutnya untuk fungsi aktivasi pada lapisan tersembunyi digunakan pada proses pelatihan adalah logsig, dan fungsi aktivasi pada lapisan keluaran adalah purelin. Bobot diambil dari nilai random yang cukup kecil, biasanya bobot awal diinisialisasi dengan nilai antara $-0,5$ sampai 0,5 (atau -1 sampai 1) [18]. Setelah melakukan trial and error, maka nilai yang tepat untuk dijadikan bobot awal yaitu 0.05 dan 0.08. Parameter Momentum berguna untuk menurunkan gradient dengan momentum dengan memberi nilai 0.9 sesuai default. Dengan melakukan perubahan momentum akan berdampak terhadap waktu proses, jadi semakin besar nilai momentum maka semakin cepat waktu proses yang terjadi [28]. Karena menggunakan proses trial and error maka momentum dilakukan dengan rentang nilai dari 0.5 - 0.9 .

Parameter epoch (iterasi) sebagai parameter perulangan untuk pemberhentian pada proses pelatihan. Apabila jumlah iterasi telah mencapai jumlah maksimum maka pelatihan akan berhenti. Pada penelitian ini menentukan maksimum 1000 epochs untuk mendapatkan hasil yang baik, sesuai dengan default fungsi pelatihan variabel laju pemahaman traingdx. Jika maksimum epoch tinggi, maka memerlukan waktu yang lama dalam melakukan pelatihan dan jika epoch rendah, maka tidak dihasilkan akurasi yang baik. Dengan menggunakan proses trial and error maka diberi rentang 100 hingga 150 epochs, karena dengan dengan sitem/aplikasi ini dapat memungkinkan iterasi yang tidak terlalu besar namun bisa mencapai hasil yang baik. Parameter laju pembelajaran (learning rate) berguna untuk mempercepat laju iterasi (epoch). Bila nilai learning rate-nya semakin kecil, maka ketelitian/ keakuratan akan semakin besar, namun terdapat resiko yaitu proses iterasi akan memakan waktu yang semakin lama. Karena jumlah learning rate ditentukan dengan proses trial and error maka rentang nilai untuk learning rate adalah 0,1 hingga 0.5 .

\subsection{Implementasi Aplikasi Pengujian}

Implementasi aplikasi pengujian dirancang menggunakan tampilan seperti pada gambar 3. Dengan adanya GUI (graphicuser interface) memudahkan user dalam menggunakan aplikasi yang sudah dibangun [29], Dari hasil pengujian dapat ditunjukkan bahwa pada halaman prediksi terdapat pop up mеnu untuk memilih untuk memprediksi data latih atau data uji yang telah di input-kan sebelumnya pada Microsoft Excel. Setelah data uji atau data input dipilih, lalu input nilai-nilai pada setiap parameter yaitu, Epoch, Learning Rate, Momentum, dan Hidden Layer.

Pengujian aplikasi dilakukan dengan menjalankan program dan melakukan proses prediksi sesuai dengan nilai-nilai input setiap paramater yang terdapat pada rancangan model prediksi tabel 4 yaitu sebanyak 75 kali untuk mendapatkan hasil akurasi yang tinggi dan nilai error yang rendah. Sehingga tingkat keakuratan sistem akan bergantung dari hasil yang diperoleh. Penentuan parameter model prediksi dilakukan terhadap arsitektur jaringan saraf tiruan terbaik pada hasil uji coba (trial and error) [30]. Tujuan uji coba parameter adalah untuk mendapatkan nilai prediksi yang baik dengan mengetahui nilai parameter paling optimal menggunakan Mean Absolute Percentage Error (MAPE) [31] dengan menggunakan model yang telah dibentuk sebelumnya. Nilai MAPE didapatkan dengan membandingkan hasil prediksi dengan data aktual, semakin kecil nilai MAPE maka semakin baik kinerja prediksi.

\subsection{Prediksi Produksi Padi}

Berdasarkan hasil pengujian sistem terhadap rancangan model parameter-parameter yang telah ditentukan, maka diperoleh parameter yang menghasilkan nilai MAPE terkecil dan akurasi terbesar, yaitu dengan epoch sebesar 200, momentum sebesar 0,5 dan learning rate sebesar 0,5 . Nilai MAPE yang didapatkan yaitu $11,86 \%$ dan nilai akurasi atau keakuratan prediksi sebesar $88,14 \%$ dengan akurasi tertinggi mencapai 98,89\%. Hasil ini sangat baik dengan perolehan akurasi yang tinggi. Sebelumnya juga ada dengan akurasi yang bervariasi [4] untuk beragam metode [32]. Untuk satu algoritma menghasilkan output dengan tingkat akurasi yang tidak sama juga.

Hasil prediksi ini bisa juga dibandingkan dengan beberapa hasil prediksi produksi padi menggunakan Backpropagation Neural Network dengan akurasi mencapai $89,56 \%$ pada [33] dan juga $94,90 \%$. Sedangkan untuk desainnya dengan menggunakan jumlah neuron yang sama untuk inputnya yaitu 3 neuron, dan hidden layernya 4 , learning rate 0,8 . 


\section{KESIMPULAN}

Rancangan arstitektur Artificial Neural Network (ANN) sudah berhasil dibuat dan diterapkan untuk prediksi produksi padi di Sumatera Barat, Indonesia. Rancangan ANN yang menggunakan multilayer pada aplikasi sudah berhasil diujikan dengan memperolah hasil prediksi produksi padi untuk periode berikutnya. Dari implementasi sistem yang dirancang, diperoleh hasil prediksi dengan akurasi mencapai $88,14 \%$. Patut dicatat bahwa proses trial dan error perlu mendapat perhatian untuk mendapatkan hasil yang maksimal dengan durasi waktu yang lebih baik. Aplikasi prediksi produksi padi yang dibuat telah mampu melakukan prediksi produksi padi untuk tahun 2018 dengan melakukan 75 kali pengujian terhadap paramater yang terdapat pada rancangan model prediksi sehingga didapatkan model dengan parameter yang optimal meliputi, input layer berjumlah 3, hidden layer berjumlah 3, dan output layer berjumlah 1 dengan epoch sebesar 200, momentum sebesar 0,5, dan learning rate sebesar 0,5 .

\section{DAFTAR PUSTAKA}

[1] H. Sutanta, A. R. Gunawan, and Y. Wibisono, "Calculation of rice field embankment coefficient using high-resolution satellite imagery," IOP Conf. Ser. Earth Environ. Sci., vol. 500, p. 012049, Jul. 2020.

[2] Badan Pusat Statistik, "Luas Panen dan Produksi Padi di Indonesia 2019 Hasil Survey Kerangka Sampel Area (KSA)," $2020 . \quad$ [Online]. Available: https://www.bps.go.id/website/materi_ind/materiBrsInd -20200204112508 .pdf.

[3] M. Al-Amin, D. Z. Karim, and T. A. Bushra, "Prediction of rice disease from leaves using deep convolution neural network towards a digital agricultural system," 2019 22nd International Conference on Computer and Information Technology, ICCIT 2019. 2019.

[4] D. Shah, H. Isah, and F. Zulkernine, "Stock market analysis: A review and taxonomy of prediction techniques," Int. J. Financ. Stud., vol. 7, no. 2, 2019.

[5] H. Putra, N. U. Walmi, and A. D. Kartika, "Data Mining Approach For Prediction Of Rice Production Using Backpropagation Artificial Neural Network Method," in The International Conference on ASEAN 2019, 2019, pp. 321-326.

[6] N. R. Dzakiyullah, B. Hussin, C. Saleh, and A. M. Handani, "Comparison neural network and support vector machine for production quantity prediction," $A d v$. Sci. Lett., vol. 20, no. 10-12, pp. 2129-2133, 2014.

[7] S. García, J. Derrac, J. R. Cano, and F. Herrera, "Prototype selection for nearest neighbor classification: Taxonomy and empirical study," IEEE Trans. Pattern Anal. Mach. Intell., vol. 34, no. 3, pp. 417-435, 2012.

[8] G. F. Fan, Y. H. Guo, J. M. Zheng, and W. C. Hong, "Application of the weighted k-nearest neighbor algorithm for short-term load forecasting," Energies, vol. 12 , no. $5,2019$.

[9] N. A. Almansour et al., "Neural network and support vector machine for the prediction of chronic kidney disease: A comparative study," Comput. Biol. Med., vol. 109, no. October 2018, pp. 101-111, 2019.

[10] S. M. Gorade and P. A. Deo, "A Study Some Data Mining Classification Techniques," Int. J. Mod. Trends Eng. Res., vol. 4, no. 1, pp. 210-215, 2017.

[11] J. Fei and C. Lu, Adaptive Sliding Mode Control of

106 Hasdi Putra
Dynamic Systems Using Double Loop Recurrent Neural Network Structure, vol. 29, no. 4. 2018.

[12] B. Das, B. Nair, V. K. Reddy, and P. Venkatesh, "Evaluation of multiple linear, neural network and penalised regression models for prediction of rice yield based on weather parameters for west coast of India," Int. J. Biometeorol., vol. 62, no. 10, pp. 1809-1822, 2018.

[13] L. Wang, Y. Zeng, and T. Chen, "Back propagation neural network with adaptive differential evolution algorithm for time series forecasting," Expert Syst. Appl., vol. 42, no. 2, pp. 855-863, 2015.

[14] H. Elarabi, "Comparison of Different Methods of Application of Neural Network on Soil Profile of Khartoum State," Int. J. Sci. Technol. Soc., vol. 2, no. 3 , p. 59, 2014.

[15] N. A. Hamid, N. M. Nawi, R. Ghazali, and M. N. M. Salleh, "Accelerating learning performance of back propagation algorithm by using adaptive gain together with adaptive momentum and adaptive learning rate on classification problems," Int. J. Softw. Eng. its Appl., vol. 5, no. 4, pp. 31-44, 2011.

[16] O. Krestinskaya, K. N. Salama, and A. P. James, "Learning in memristive neural network architectures using analog backpropagation circuits," IEEE Trans. Circuits Syst. I Regul. Pap., vol. 66, no. 2, pp. 719-732, 2019.

[17] G. Amaral et al., Modern Database Management, vol. 369 , no. 1.2013

[18] Laurene V. Fausett, Fundamentals Of Neural Networks: Architectures, Algorithms And Applications, no. 888. 2007.

[19] O. M. Rezapour, L. T. Shui, and A. A. Dehghani, "Review of genetic algorithm model for suspended sediment estimation," Aust. J. Basic Appl. Sci., vol. 4, no. 8, pp. 3354-3359, 2010.

[20] P. C. Chang, Y. W. Wang, and C. H. Liu, "The development of a weighted evolving fuzzy neural network for PCB sales forecasting," Expert Syst. Appl., vol. 32, no. 1, pp. 86-96, 2007.

[21] P. K. Sethy, N. K. Barpanda, A. K. Rath, and S. K. Behera, "Nitrogen Deficiency Prediction of Rice Crop Based on Convolutional Neural Network," J. Ambient Intell. Humaniz. Comput., no. 0123456789, 2020.

[22] A. Wanto, A. P. Windarto, D. Hartama, and I. Parlina, "Use of Binary Sigmoid Function And Linear Identity In Artificial Neural Networks For Forecasting Population Density," IJISTECH (International J. Inf. Syst. Technol., vol. 1, no. 1, p. 43, 2017.

[23] I. N. da Silva, D. H. Spatti, R. A. Flauzino, L. H. B. Liboni, and S. F. dos Reis Alves, "Artificial neural networks: A practical course," Artif. Neural Networks A Pract. Course, pp. 1-307, 2016.

[24] G. Deshpande, P. Wang, D. Rangaprakash, and B. Wilamowski, "Fully connected cascade artificial neural network architecture for attention deficit hyperactivity disorder classification from functional magnetic resonance imaging data," IEEE Trans. Cybern., vol. 45, no. 12, pp. 2668-2679, 2015.

[25] R. B. Santos, M. Rupp, S. J. Bonzi, and A. M. F. Fileti, "Comparison between multilayer feedforward neural networks and a radial basis function network to detect and locate leaks in pipelines transporting gas," Chem. Eng. Trans., vol. 32, pp. 1375-1380, 2013.

[26] A. A. Heidari, H. Faris, I. Aljarah, and S. Mirjalili, "An efficient hybrid multilayer perceptron neural network with grasshopper optimization," Soft Comput., vol. 23, no. 17, pp. 7941-7958, 2019.

[27] F. S. Panchal and M. Panchal, "Review on Methods of Selecting Number of Hidden Nodes in Artificial Neural 
Network," Int. J. Comput. Sci. Mob. Comput., vol. 311, no. 11, pp. $455-464,2014$.

[28] V. T. Widyaningrum and A. S. Romadhon, "Pengaruh Pemberian Momentum Pada," Semin. Nas. Sains dan Teknol. 2014, no. November, 2014.

[29] V. Prema and K. Uma Rao, "Interactive Graphical User Interface (GUI) for Wind Speed Prediction Using Wavelet and Artificial Neural Network," J. Inst. Eng. Ser. B, vol. 99, no. 5, pp. 467-477, 2018.

[30] A. Rohani, M. H. Abbaspour-Fard, and S. Abdolahpour, "Prediction of tractor repair and maintenance costs using Artificial Neural Network," Expert Syst. Appl., vol. 38, no. 7, pp. 8999-9007, 2011.

[31] E. Lee, Y. D. Seo, and Y. G. Kim, "Self-adaptive framework based on MAPE loop for internet of things," Sensors (Switzerland), vol. 19, no. 13, pp. 1-24, 2019.

[32] Z. CÖMERT and A. KOCAMAZ, "A Study of Artificial Neural Network Training Algorithms for Classification of Cardiotocography Signals," Bitlis Eren Univ. J. Sci. Technol., vol. 7, no. 2, pp. 93-103, 2017.

[33] G. Ramadhona, B. D. Setiawan, and F. A. Bachtiar, "Prediksi Produktivitas Padi Menggunakan Jaringan Syaraf Tiruan Backpropagation," J. Pengemb. Teknol. Inf. dan Ilmu Komput., vol. 2, no. 12, pp. 6048-6057, 2018. 